\title{
Treatment of chronic ear infection with polyposis - a
} case report

\section{Abstract}

In elderly patients, with high risk of morbidity and mortality, a surgical procedure should not be the first option in treatment of chronic ear infection with polyposis. An alternative conservative attitude is offered, by use of low-dose of immunomodulation therapy.
Volume 7 Issue 6 - 2017

Dunja Milicic

Department of Otorhinolaryngology, Hospital da Luz Arrabida, Portugal

Correspondence: Dunja Milicic, Hospital da Luz Arrabida, Department of Otorhinolaryngology, Porto, Portugal, Emaildunja_ruz_bara@hotmail.com

Received: March 19,2017| Published: June 26, 2017

\section{Introduction}

The long term result of surgical treatment of chronic ear disease with polyposis is, in many cases doubtful ${ }^{1}$. An option of medical treatment is offered.

\section{Method and materials}

The patient was M.E.M., 50years old, ASA1, female with chronic ear disease with polyposis of the right ear; with moderate type I (50dB HL) conductive hearing loss. A CT scan is presented on Figure 1 \& 2. The treatment was initiated after written informed consent, with amoxicillin and clavulanic acid $(875 \mathrm{~m}+125 \mathrm{mg})$ in a form of $1 / 2$ pill twice per day and prednisolone $5 \mathrm{mg} /$ day.

The treatment was performed during two months with repetition of CT scan of the ear on the end of the treatment.

\section{Results}

There was no negative effect of medication on the patient during the treatment. After two months of treatment, the normal hearing was restored and type A of tympanogram was obtained. The results of CT scan image of the ear are presented on Figure $3 \& 4$.

\section{Discussion}

There is no doubt that in any case of cholesteatoma a surgery is the best option. ${ }^{2}$ However, in the presence of polyposis of the middle ear disease, the surgery is not always a final resolution. ${ }^{1,2}$

Major objections are, as it is known: a need of two stage surgery, an uncertain surgical result with reconstruction techniques, a procedure subjected to pathological scaring, and all that resulting in poor functional results. In my practice, I am facing an ageing population with multiple diseases, majority of them with ASA. ${ }^{3}$

This fact makes anesthesia, with its needs of prolonged controlled hypotension, a procedure of high risks, often resulting in cerebracardio-vascular complications and, equally important: most of these patients are not reluctant but they explicitly do not want to be submitted to any kind of surgery, not even colocation of ventilation tubes, due to high morbidity and mortality in this group of patients.

The purpose of this presentation was to try a non-aggressive/ non-surgical treatment for resolution of this clinical entity without violating the medical condition of these patients and, not less important, following their wish on the type of treatment to be used.

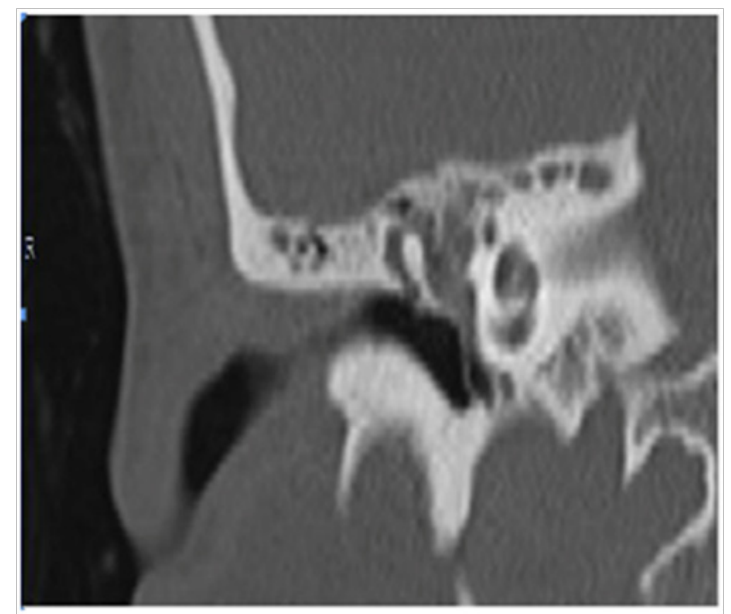

Figure I MEM, 50 yrs female, OMC with polyps, R ear before treatment.

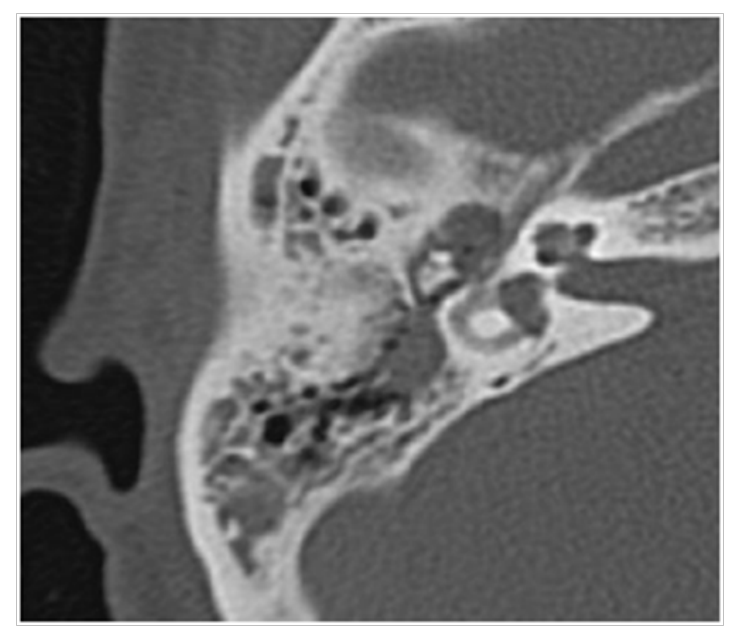

Figure 2 MEM, 50 yrs female, OMC wit polyps, $\mathrm{R}$ ear before treatment.

The medical treatment of chronic nasal sinus disease with polyposis is an option..$^{3-8}$ The use of clarithromycin as immunosuppressive drug 
is encouraged. In this case, it was used a broad-spectrum antibiotic, ${ }^{3}$ due to poor results obtained in treatments using clarithromycin of sinusitis with polyps.

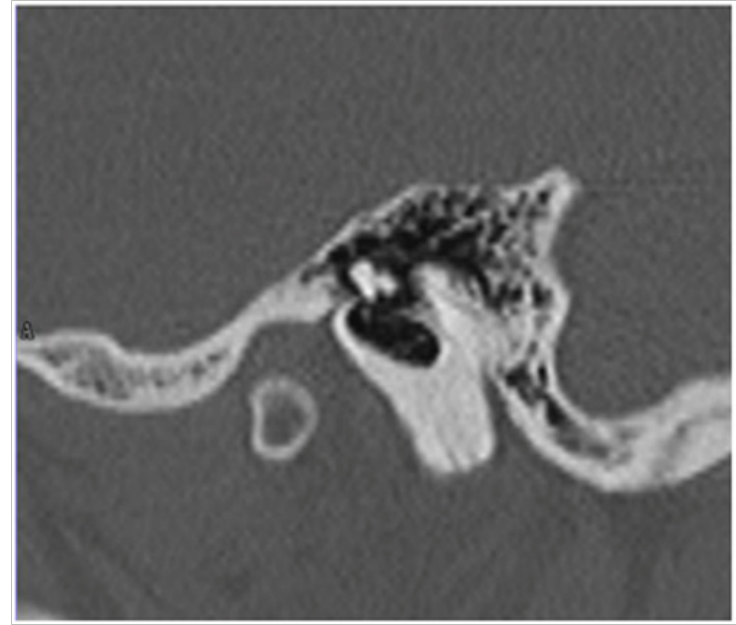

Figure 3 MEM, 50 yrs female, OMC with polyps, R ear after treatment.

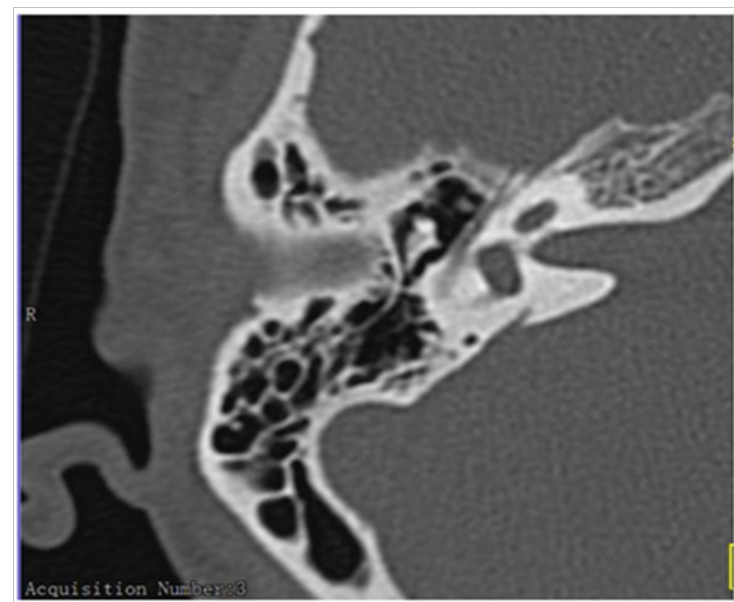

Figure 4 M EM, 50 yrs, female, OMC with polyps.

As immunosuppressive drug the option was a low-dose prednisolone with its glucocorticoid effect. ${ }^{9,10}$ As it is visible in the Figure $3 \& 4$, a resolution of the disease is obtained with no need for surgery. The patient had no recurrence of the ear disease.

\section{Conclusion}

A surgery is not only solution for chronic ear disease with polyposis. In certain group of patients, an alternative conservative treatment could be an option.

\section{Acknowledgments}

None.

\section{Conflicts of interest}

Author declares there are no conflicts of interest.

\section{Funding}

None.

\section{References}

1. Brackmann D, Shelton C, Moses. Otologic surgery (4th edn). Elsevier Health Sciences, Elsevier, USA. 2005.

2. Sheehy JL, Brackmann DE, Graham MD. Cholesteatoma surgery: residual and recurrent disease: a review of 1,024 cases. Ann Otol Rhinol Laryngol. 1977;86(4 pt 1):451-462.

3. Steinman MA, Landefeld CS, Gonzales R. Predictors of broad-spectrum antibiotic prescribing for acute respiratory tract infections in adult primary care. JAMA. 2003;289(6):719-725.

4. Misato H, Mitushiro O, Yasuyuki N, et al. A historical cohort study of eosinophilic inflammation in chronic rhinosinusitis with nasal polyps in Okayama, Japan. Clinical and Translational Allergy. 2013;3(Suppl 2):O3.

5. Okano. Cellular responses to Staphylococcus aureus alpha-toxin are associated with clinical outcomes in chronic rhinosinusitis with nasal polyps. Clinical and Translational Allergy. 2013;3(Suppl 2):P25.

6. Ichimiya I, Kawauchi H, Mogi G. Analysis of immunocompetent cells in the middle ear mucosa. Archives of Otolaryngology-Head \& Neck Surgery. 1990;116(3):324-330.

7. Gillespie MB, Osguthorpe JD. Pharmacologic management of chronic rhinosinusitis, alone or with nasal polyposis. Curr Allergy Asthma Rep . 2004;4(6):478-485.

8. Temple ME, Nahata MC. Pharmacotherapy of acute sinusitis in children American journal of health-system pharmacy. 2000;57(7):663-668.

9. Docken WP. Low-dose prednisone therapy. Rheumatic diseases clinics of North America. 1989;15(3):569-576.

10. Da Silva JA, Jacobs JW, Kirwan JR, et al. Safety of low dose glucocorticoid treatment in rheumatoid arthritis: published evidence and prospective trial data. Ann Rheum Dis. 2006;65(3):285-293. 